\title{
Managing Anxiety and Stress Holistically: Vedic Wisdom from the Purna
}

\section{Health Management System}

\author{
Emily Schulz*
}

Department of Occupational Therapy, Northern Arizona University, College of Health and Human Services, USA

*Corresponding author: Schulz E, Assistant Clinical Professor, Department of Occupational Therapy, Northern Arizona University, College of Health and Human Services, Phoenix, Arizona, USA, Tel: 602-827-2667; E-mail: emily.schulz@nau.edu

Received: December 23, 2020; Accepted: January 07, 2021; Published: January 15, 2021

\begin{abstract}
Background: Anxiety and stress are prevalent across the globe. The Purna Health Management System (PHMS), named for its creator Dr. Professor Svami Purna, provides a promising approach to managing anxiety and stress, using four key factors in a holistic integrated method: Health, Fitness and Nutrition (HF\&N), Life Balance (Stress Management) (LB-SM), Spiritual Growth and Development (SG\&D) and Living in Harmony with the Natural Environment to Support Health (LHWNE).

Objective: To determine which of the four key factors of the PHMS correlate to participants' overall stress, stress management and mental/emotional health outcomes and which practices are helpful in managing stress and anxiety.

Methods: This was a cross-sectional mixed-methods study using an online anonymous survey with a non-clinical sample. Students of Dr. Professor Svami Purna were invited via email to participate in the study during a 12-month period in 20172018. Of the 253 approached, 60 responded to the survey. Spearman's Rho Correlation coefficient was used for analysis.

Results: There were moderate relationships ( $p$.001) between participants' frequent implementation of the PHMS four key factors and ability to manage stress $(\mathrm{HF} \& \mathrm{~N}$ rs = 0.44; LB-SM rs = 0.55; SG\&D rs = 0.39; LHWNE rs $=0.55)$ and self-reported mental/emotional health $($ HF\&N rs = 0.42; LB-SM rs = 0.54; SG\&D rs = 0.49; LHWNE rs = 0.45). Illustrative quotes from qualitative data indicated being in nature, contemplation, introspection, mantra, meditation, pranayama and reflection are helpful practices for managing stress and anxiety.

Conclusion: The PHMS may help clients to self-manage anxiety and stress.
\end{abstract}

Keywords: Anxiety management; Stress management; Emotional balance; Mental balance; Integrated; Holistic; Vedic philosophy 
www.yumedtext.com | January-2021 | ISSN: 2582-3264 | https://dx.doi.org/10.46527/2582-3264.130

\section{Introduction}

The Purna Health Management System (PHMS) is an integrative, holistic approach based in ancient Vedic philosophy from the Sindo-Gangetic civilization. Created by the Himalayan Master, Professor, Dr. Svami Purna [1], it provides guidance on how people can live a healthy fulfilling life physically, mentally, emotionally, and spiritually, while taking responsibility for their own holisitc health management. The PHMS involves 4 key factors that are integrated with each other in a transactive fashion: Health, Fitness and Nutrition (HF\&N), Life Balance (Stress Management) (LB-SM), Spiritual Growth and Development (SG\&D) and Living in Harmony with the Natural Environment to Support Health (LHWNE).

\subsection{Literature supporting the PHMS 4 key factors}

An explanation of the recommendations provided from each of the PHMS 4 Key Factors: Health, Fitness and Nutrition $(H F \& N)$, Life Balance (Stress Management) (LB-SM), Spiritual Growth and Development (SG\&D) and Living in Harmony with the Natural Environment to Support Health (LHWNE), is below. Literature regarding each of the PHMS 4 Key Factors and their relationship with the management of stress and anxiety follows each explanation.

\subsection{Health, fitness and nutrition $(\mathrm{HF} \& \mathrm{~N})$}

The PMHS Key Factor of Health, Fitness and Nutrition recommends that we engage in moderate exercise every day, eat a plant-based diet, and get 6-8 hours of deep, restful, undisturbed sleep [2-12]. Research supports these recommendations for the management of stress and anxiety [13-15].

For Health, Fitness, and Nutrition, recent research suggests that anxiety and stress decrease with physical exercise [16-19]. Similarly, proper nutrition is important during times of increased stress [20-21]. A plant-based diet was found to be associated with better health-related quality of life and mental health [22-23]. Getting the proper amount of Sleep is associated with decreased anxiety and stress [24-25].

\subsection{Life balance (stress management) (LB-SM)}

The PHMS Key Factor of Life Balance (Stress Management) suggests that we maintain a proper work and home life balance, engage in wholesome creative activities, and communicate with others in a calm, balanced, relaxed way [2-12].

Literature indicates that work-life balance has been found to support decreased anxiety and stress in college students [26].

Male pharmacy faculty report lower levels of anxiety and stress and better work-life balance than their female counterparts, suggesting an association between work-life balance with anxiety and stress [27].

Research also suggests that balanced interpersonal communication, a part of stress management, is associated with positive health and mental health outcomes in certain populations [28-29].

\subsection{Spiritual growth and development (SG\&D)}

The PHMS Key factor of Spiritual Growth and Development follows Patanjali's 8-limbs of yoga [30]. Recommended practices include meditation, prayanama, mantra, reflection, contemplation and introspection. Recent literature addresses the benefits of 
www.yumedtext.com | January-2021 | ISSN: 2582-3264 | https://dx.doi.org/10.46527/2582-3264.130

meditation, pranayama, mantra and reflection and are explored further. Meditation has been found to support decreased stress and anxiety [31-33]. Recent research also indicates that Pranayama (breathwork) is helpful in managing stress and anxiety in several populations [34-36]. The literature suggests that mantra is an effective practice for managing stress and anxiety [3740]. Research indicates that those who engage in reflection during a stressful experience are more resilient and have better well-being [41].

\subsection{Living in harmony with the natural environment to support health (LHWNE)}

The PHMS Key Factor of Living in Harmony with the Natural Environment to Support Health involves spending time in nature, having reverence for nature, and protecting and sustaining nature. Recent evidence addresses the benefits of being in nature relative to managing stress and anxiety [2-12].

Research suggests that being out in nature is helpful in decreasing stress and anxiety [42], and increasing emotional wellbeing [43]. Even use of virtual environments are helpful when the natural environment is not readily accessible [44-45].

Since the PHMS is holistic and integrates all aspects of the person, it fits well with the current trends toward integrated behavioral health [46] and integrative medicine approaches to health care [47]. The PHMS not only integrates Eastern and Western perspectives of healing found in integrative medicine, but also supports integrating behavioral health and physical health together. This is important as physical health and behavioral health can strongly influence each other [48-52].

\section{Statement of the Problem}

Currently, levels of anxiety and stress have been on the rise across the globe, which has been exacerbated recently with the advent of COVID-19 and the mandate to social distance [53-56]. There is a need for non-pharmaceutical approaches to be more fully incorporated into interventions to help ameliorate anxiety and stress [57]. The PHMS suggests practices that can address this need and provides individuals with the tools for self-management.

\section{Objectives}

The purpose of this study was twofold:

1) to determine which of the four key factors of the PHMS have a statistically significant relationship with participants' stress management and mental/emotional health outcomes, and

2) to determine which PHMS practices are perceived by participants as being helpful in managing stress and anxiety.

\section{Methods}

This study was a cross-sectional mixed-methods descriptive study using an anonymous online survey.

\subsection{Study site}

The study was conducted online using SurveyMonkey.

\subsection{Study population}

This is a non-clinical population, comprised of 253 students of Professor Dr. Svami Purna. 


\subsection{Eligibility criteria}

To be eligible for the study, potential participants needed to be adults over the age of 18 and students of Professor Dr. Svami Purna.

\subsection{Inclusion criteria}

Adult students of Professor Dr. Svami Purna were included in the study.

\subsection{Exclusion criteria}

Students of Professor Dr. Svami Purna who were younger than 18 years old, people who were not students of Professor Dr. Svami Purna and people who were younger than 18 years old, were excluded from the study.

\subsection{Sample size}

Of the 253 potential participants who were invited to participate in the study, 60 people responded to the survey, which is a $24 \%$ response rate.

\subsection{Research design}

This study used a mixed-methods explanatory sequential research design incorporating both quantitative and qualitative (openended) questions in an online survey. The quantitative items came first in the survey, followed by the qualitative open-ended questions to gain an understanding of the quantitative responses.

\subsection{Study participant recruitment and enrollment}

Potential participants who were adult students of Professor Dr Svami Purna were invited via email to participate. The email explained the purpose of the study, and that it was anonymous and voluntary. A link to the online survey was provided in the email. Once a participant clicked on the link, they were provided again with information about the study and reminded that it was anonymous, voluntary, and that they could stop participating at any time for any reason. They were given an option to agree to participate or not. Only 1 person chose not to participate, leaving 60 respondents remaining.

\subsection{Data collection methods}

Data were collected using an anonymous online survey.

\subsection{Study implementation}

The study was approved by A.T. Still University's IRB in Mesa, Arizona, USA. Potential participants were emailed approximately every 3-4 weeks during a 1-year period in 2017-2018, inviting them to respond to the survey.

\subsection{Study instruments}

Due to its unique focus, this study used a survey created by the researcher, which was reviewed by a panel of experts before implementation of the study to increase face validity. 
www.yumedtext.com | January-2021 | ISSN: 2582-3264 | https://dx.doi.org/10.46527/2582-3264.130

\subsubsection{Survey with Likert Scale and open-ended questions}

This study used a survey comprised of a demographic module, Likert Scale questions, and open-ended questions. Some of the Likert scale questions addressed the Frequency of Implementation of the 4 Key Factors. For example: "In general, how often do you implement the PHMS teachings about Life-Balance (Stress Management) into your life?" using the 6-point rating scale of Daily, Several Times a Week, Weekly, Monthly, Less than once a month, Not applicable. This method was used for all PHMS 4 Key Factors. Other Likert scale questions asked for participant's stress and health outcomes. Overall Stress was measured by this item: "In general, during the past 12 months, what has been the overall amount of stress you have experienced in life?" A 6-point Likert scale was used to rate this item: No stress, very little stress, mild stress, moderate stress, quite a lot of stress, extreme stress. Ability to Manage Stress was measured by the item: "In general, how would you rate yourself on your ability to manage that stress?" Physical Health was measured with this question "My overall physical health on most days, taking into account intensity of physical pain and other symptoms, frequency of physical illness, fatigue and general energy level is" Mental/Emotional Health was measured by this item: "My overall mental health on most days, taking into account intensity of emotional pain and other symptoms, mood swings, mental clarity and general stress level is." A 5-point Likert scale of Excellent, Very Good, Good, Fair, and Poor was used to rate the outcomes of Ability to Manage Stress, Physical Health, and Mental/Emotional Health.

The open-ended question of "please explain" appeared after each Likert Scale question. At the end of the quantitative section of the survey, several open-ended questions were also asked such as "How have the PHMS Teachings helped you in managing stress? (please be specific and give examples)" and "How have the PHMS Teachings helped you in managing anxiety? (please be specific and give examples)" It is from this last section of questions that the illustrative quotes in the findings for this study are gleaned.

\subsection{Findings}

Demographic characteristics of the study sample are found in TABLE 1. Quantitative findings are in TABLE 2. Qualitative Themes for the open-ended questions using illustrative quotes are shown in TABLE 3.

TABLE 1. Demographic Characteristics of Study Sample (N=60).

\begin{tabular}{|c|c|}
\hline Variable & $\mathbf{N}(\%)$ \\
\hline Age $^{\mathrm{a}}$ & \\
$31-39$ & $9(15.00 \%)$ \\
$40-49$ & $22(36.66 \%)$ \\
$50-59$ & $15(25.00 \%)$ \\
$60-69$ & $7(11.66 \%)$ \\
$70-78$ & $4(6.67 \%)$ \\
Age not stated & $3(5.00 \%)$ \\
\hline Gender & \\
Male & $14(23.33 \%)$ \\
Female & $44(73.33 \%)$ \\
Gender not stated & $2(3.33 \%)$ \\
\hline
\end{tabular}




\begin{tabular}{|c|c|}
\hline Race/Ethnicity & \\
\hline White & $40(66.67 \%)$ \\
\hline Hispanic/Latino & $10(16.67 \%)$ \\
\hline Black or African American & $1(1.67 \%)$ \\
\hline Would Rather Not Say & $4(6.67 \%)$ \\
\hline Other & $4(6.67 \%)$ \\
\hline Race/Ethnicity not stated & $1(1.67 \%)$ \\
\hline \multicolumn{2}{|l|}{ Annual Household Income ${ }^{b}$} \\
\hline$\$ 0-80,000$ & $24(40.00 \%)$ \\
\hline$\$ 90,000-300,000$ & $16(26.67 \%)$ \\
\hline Annual Household Income not stated & $20(33.33 \%)$ \\
\hline \multicolumn{2}{|l|}{ Employment Status } \\
\hline Self-Employed & $22(36.66 \%)$ \\
\hline Full Time & $17(28.33 \%)$ \\
\hline Retired & $11(18.33 \%)$ \\
\hline Part Time & $7(11.66 \%)$ \\
\hline Unemployed & $1(1.67 \%)$ \\
\hline Employment Status not stated & $2(3.33 \%)$ \\
\hline \multicolumn{2}{|l|}{ Education Level } \\
\hline Some College Courses & $3(5.00 \%)$ \\
\hline Associate's Degree & $2(3.33 \%)$ \\
\hline Bachelor's Degree & $15(25.00 \%)$ \\
\hline Some Graduate Courses & $5(8.33 \%)$ \\
\hline Master's Degree & $21(35.00 \%)$ \\
\hline Doctorate & $7(11.67 \%)$ \\
\hline Education Level not stated & $2(3.33 \%)$ \\
\hline \multicolumn{2}{|l|}{ Marital Status } \\
\hline Married/Legally Partnered & $22(36.66 \%)$ \\
\hline Divorced & $20(33.33 \%)$ \\
\hline Never Been Married & $9(15.00 \%)$ \\
\hline A Member of an Unmarried Couple & $5(8.33 \%)$ \\
\hline Other (Single) & $2(3.33 \%)$ \\
\hline Prefer not to Say & $1(1.67 \%)$ \\
\hline Marital Status not Stated & $1(1.67 \%)$ \\
\hline \multicolumn{2}{|l|}{ Raising Children } \\
\hline Yes & $20(33.33 \%)$ \\
\hline No & $39(65.00 \%)$ \\
\hline Parental Status not stated & $1(1.67 \%)$ \\
\hline
\end{tabular}




\begin{tabular}{|c|c|}
\hline Raising Children under 18 & \\
Yes & $16(26.67 \%)$ \\
No & $43(71.66 \%)$ \\
Children under 18 not stated & $1(1.67 \%)$ \\
\hline${ }^{a}$ Mean Age $=49.82, \mathrm{SD}=11.28 ;{ }^{b}$ Mean Annual Household Income $\left.=\$ 84,876.25, \mathrm{SD}=\$ 78974.76\right)$
\end{tabular}

TABLE 2. Spearman's Rho Correlations for Frequency of Implementation of PHMS 4 Key Factors and Outcome Variables $(\mathbf{N}=52)$.

\begin{tabular}{|c|c|c|c|c|}
\hline $\begin{array}{c}\text { Frequency of } \\
\text { Implementation of } \\
\text { PHMS Factor }\end{array}$ & $\begin{array}{c}\text { Overall Stress Past } \\
\mathbf{1 2} \text { months }\end{array}$ & $\begin{array}{c}\text { Ability to Manage } \\
\text { Stress }\end{array}$ & Physical Health & $\begin{array}{c}\text { Mental/Emotional } \\
\text { Health }\end{array}$ \\
\hline $\begin{array}{c}\text { Health Fitness and } \\
\text { Nutrition }\end{array}$ & 0.21 & $0.44^{* *}$ & 0.24 & $0.42^{* *}$ \\
\hline $\begin{array}{c}\text { Life Balance (Stress } \\
\text { Management) }\end{array}$ & 0.15 & $0.55^{* *}$ & $0.28^{*}$ & $0.54^{* *}$ \\
\hline $\begin{array}{c}\text { Spiritual Growth } \\
\text { and Development }\end{array}$ & 0.14 & $0.39^{* *}$ & 0.14 & $0.49^{* *}$ \\
\hline $\begin{array}{c}\text { Living in Harmony } \\
\text { with the Natural } \\
\text { Environment to } \\
\text { Support Health }\end{array}$ & $0.28^{*}$ & $0.55^{* *}$ & 0.18 & $0.45^{* *}$ \\
\hline
\end{tabular}

*. Correlation is significant at the 0.05 level (2-tailed).**. Correlation is significant at the 0.01 level (2-tailed).

TABLE 3. Illustrative Quotes of Helpful PHMS Practices.

\begin{tabular}{|c|l|}
\hline \multicolumn{1}{|c|}{$\begin{array}{c}\text { PHMS Key } \\
\text { Factor }\end{array}$} & \multicolumn{1}{c|}{ Illustrative Quotes of Helpful PHMS Practices } \\
\hline and Nutrition & $\begin{array}{l}\text { Diet } \\
\text { "I am careful about diet and avoid certain exposures" } \\
\text { "Green Juices everyday, when possible...eating organic as much as I can.... Detoxifying the } \\
\text { body, fasting very important (the body ask for it naturally)." } \\
\text { "organic whole foods keep the body stable and less reactive" } \\
\text { "Eating as much organic as possible and trying to go 100\% vegetarian." } \\
\text { Exercise } \\
\text { "Exercises every day... Yoga poses." } \\
\text { Sleep } \\
\text { "Better sleep so important" }\end{array}$ \\
(Stress & $\begin{array}{l}\text { Stress Management: } \\
\text { "Stress naturally falls away as emotional balance increases." }\end{array}$ \\
\hline
\end{tabular}




\begin{tabular}{|c|c|}
\hline & $\begin{array}{l}\text { "keeping calm in the midst of the storm in any area of life, keep breathing, not taking anything } \\
\text { personal, being positive, seeing thing as a learning process." } \\
\text { "Focus daily on maintaining life balance so I can continue on" } \\
\text { "Balancing work and personal life to maintain physical health balance." }\end{array}$ \\
\hline $\begin{array}{c}\text { Spiritual } \\
\text { Growth and } \\
\text { Development }\end{array}$ & 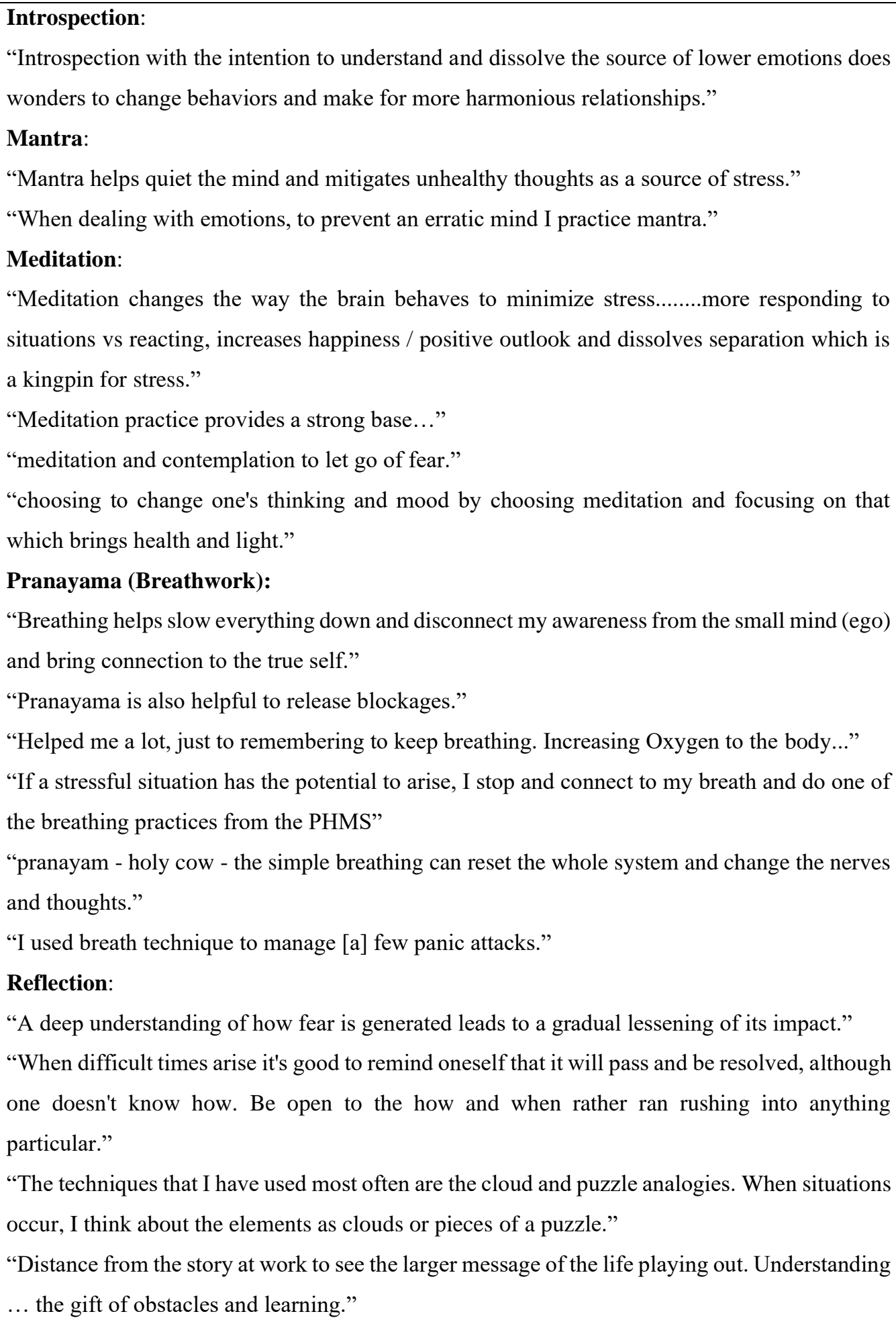 \\
\hline $\begin{array}{r}\text { Livin } \\
\text { Harmon }\end{array}$ & $\begin{array}{l}\text { Being in Nature: } \\
\text { "walking outside and listening to sounds of nature is very soothing and uplifting." }\end{array}$ \\
\hline
\end{tabular}


www.yumedtext.com | January-2021 | ISSN: 2582-3264 | https://dx.doi.org/10.46527/2582-3264.130

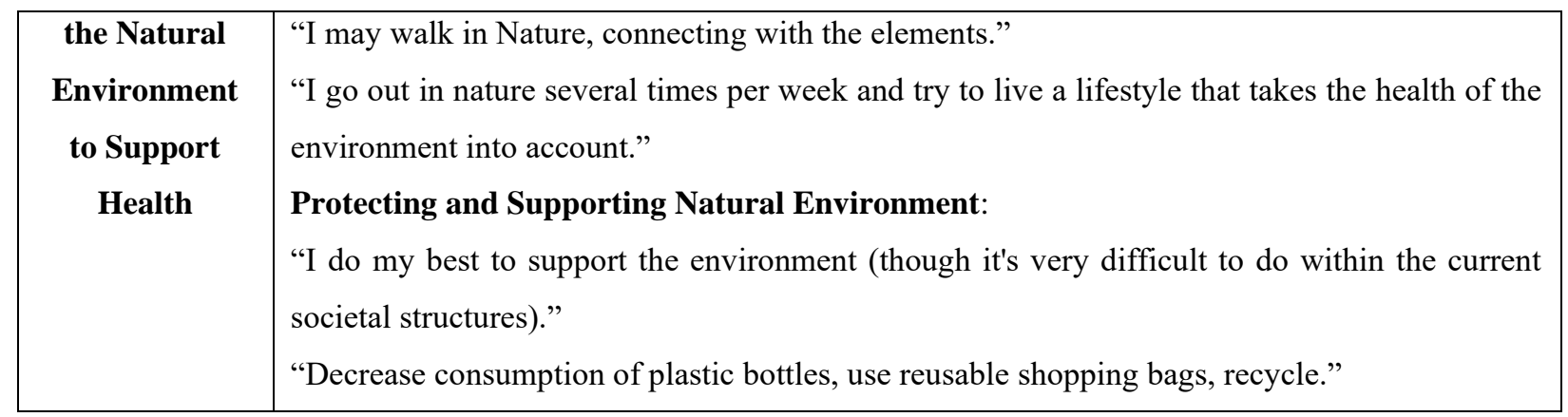

\subsubsection{Demographic characteristics of the study sample}

Descriptive characteristics of the sample were calculated and are reported using number count (n) and percent (\%). The mean age of the study sample was 49.82 years, with an age range of 31-78. Most of the respondents were female 44(73.33\%) and White 40(66.67\%). Only 40 of the 60 participants responded to the annual household income item, which ranged from $\$ 0$ $\$ 300,000$. More respondents $24(40 \%)$ reported a household income of $\$ 80000$ or below per year, which is below the mean of $\$ 84,876.25$. Approximately two-thirds of the sample were either self-employed 22(36.66\%) or employed full time 17(28.33\%). Many of the participants $48(80 \%)$ had a Bachelor's degree or higher for education level. For marital status, 31(51.66 \%) were without a partner and 27(45\%) were partnered. For parental status, 20(33.33\%) reported raising children, and 16(26.67\%) of them were raising minor children (under the age of 18).

\subsubsection{Quantitative findings - Spearman's Rho correlations}

Because the data were non-parametric, Spearman's Rho correlation co-efficient was used to calculate the relationships between the PHMS 4 key factors and the self-reported outcomes of overall stress, ability to manage stress, physical health, and mental/emotional health. Self-reported overall stress in the past 12 months had a weak significant association with LHWNE. Self-reported physical health had a weak significant relationship with LB-SM. There were moderate significant relationships between participants' frequent implementation of the PHMS 4 key factors and their self-reported ability to manage stress selfreported mental/emotional health.

\subsubsection{Qualitative themes organized by PHMS 4 key factors}

Deductive coding using the PHMS 4 key factors and their sub-categories was used for analysis of the qualitative data. A peer reviewer provided feedback on the categorization of the codes. Some quotes from participants' responses are below, organized by the PHMS 4 key factors and their subcategories to help further illuminate the quantitative findings and demonstrate how some of the participants were implementing the PHMS practices to manage their stress and anxiety.

\section{Discussion}

All 4 key factors of the PHMS have a moderate statistically significant relationship with participants' ability to manage stress and mental/emotional health outcomes. These findings are supported by recent evidence, suggesting that getting proper exercise, eating a nutrient-rich plant-based diet, and getting enough sleep are important factors associated with reducing stress and anxiety [16-25]. Similarly, being able to maintain a good work-life balance and communicate in a balanced way with others has a relationship with decreased anxiety and stress and increased wellbeing [26-29; 59-60]. Spiritual practices such as mantra, 
www.yumedtext.com | January-2021 | ISSN: 2582-3264 | https://dx.doi.org/10.46527/2582-3264.130

pranayama, and meditation are also related to the lowering of stress and anxiety levels [31-41; 61-63]. Finally, being in nature is correlated with reduced stress and anxiety [42-45].

It is difficult to pull apart thematically an integrated holistic approach such as the PHMS. As one participant explained, many methods used together can assist when managing anxiety: "Tools of prayer, mantra, contemplation, breath work all help to face anxiety and let it go." Another participant stated regarding managing stress: "I apply pranayama, meditation and contemplation to bring the mind into a place of calm and then to reflect on the situation or thought that is causing stress or the feeling of being unsettled...and work with those energies from that more calm and objective perspective." However, the illustrative quotes from the participants appear to suggest that using the PHMS while combining its many facets was helpful to them in finding mental and emotional balance.

These findings suggest that there is value and significance in finding ways to maintain mental and emotional balance, build resilience while managing anxiety, anger and stress given the circumstances of COVID-19 (and other crises of course) when people find themselves in a situation that is out of their control so that they can deal with life better. There is importance in developing a more philosophical perspective as suggested through the PHMS, perhaps through reframing, perhaps using humor or other uplifting tools as we cope with what life brings our way. The positive mind is so relevant to the management of stress and anxiety and to a happy, healthy life [63]. The PHMS system is flexible, integrated, and holistic and allows individuals to choose the practices which suit them best. The PHMS provides a promising approach to managing anxiety and stress. More research is needed with a larger sample size to demonstrate how the PHMS helps with the management of stress and anxiety.

\section{Conclusion}

Although we cannot attribute causality to these relationships as they are correlational in nature, the findings of this study suggest that using an integrated holistic approach such as the one provided by the PHMS may be valuable in helping people who are experiencing stress and anxiety.

\section{Acknowledgements}

The author would like to thank Sri Svami Purna Maharaj (Svamiji) for His oversight and guidance throughout and Dr. Linda Spedding for her review and guidance. Gratitude is also extended to Dr. Curt Bay for conducting the data analyses. Finally, thanks are offered to the 60 participants of this study; without their participation, this study would not have been possible.

\section{Funding}

This study was not funded.

\section{Conflicts of Interest}

None. 


\section{REFERENCES}

1. Foundation, A. HH Sri Svami Purnaji Maharaj. Hawley, PA: Adhyatmik Foundation. 2020. [https://www.adhyatmik.org/hh-sri-svami-purnaji-maharaj.html].

2. Spedding L. Purna health management system: Overview. Hawley, PA: Adhyatmik Foundation; 2012.

3. Spedding L. Balanced nutrition. Hawley, PA: Adhyatmik Foundation; 2013.

4. Spedding L. Balanced sleep. Hawley, PA: Adhyatmik Foundation; 2014.

5. Spedding L Balanced emotions. Hawley, PA: Adhyatmik Foundation; 2014.

6. Spedding L Balanced mind. Hawley, PA: Adhyatmik Foundation; 2015.

7. Purna S. Balanced yoga: The twelve-week programme. Rockport, MA: Element, USA; 1990.

8. Purna S. The truth will set you free. New Delhi: New Age Books, India; 2008.

9. Purna S. Practical wisdom. New Delhi: New Age Books, India; 2010.

10. Purna S. So you shall know the truth: A collection of discourses. New Delhi: New Age Books, India; 2013.

11. Purna S. Life: A mysterious journey. New Delhi: New Age Books, India; 2014.

12. Purna, S. Divine dialogues telecast [mp3 recording]. Hawley, PA: Adhyatmik Foundation; 2017.

13. Schulz EK. The Purna Health Management System: Vedic wisdom for everyday life (Master's Thesis, Prescott College). Prescott, Arizona. 2015.

14. Schulz EK. How a Himalayan Master and teacher promotes healthy behavior among His followers in the Vedic tradition. Int J Stud Nurs. 2017;3(1):56-67.

15. Schulz E. Perceived wellbeing as related to spirituality and stress management: A case study of the Purna health management system. J Posit Sch Psychol. 2020;4(1):1-4.

16. Blumenthal JA, Babyak MA, Craighead WE, et al. The role of comorbid anxiety in exercise and depression trials: Secondary analysis of the SMILE - II randomized clinical trial. Depress Anxiety. 2020.

17. Prieto JM. Motivation, social anxiety, physical exercise practice and academic performance. J Sport Health Res. 2020;12(Suppl 1):25-30.

18. Hallgren M, Kandola A, Stubbs B, et al. Associations of exercise frequency and cardiorespiratory fitness with symptoms of depression and anxiety-a cross-sectional study of 36,595 adults. Ment Health Phys Acti. 2020;19:100351.

19. Tanner MK, Fallon IP, Baratta MV, et al. Voluntary exercise enables stress resistance in females. Behav Brain Res. 2019;369:111923.

20. Wimalawansa SJ. Fighting against COVID-19: Boosting the immunity with micronutrients, stress reduction, physical activity, and vitamin D. Nutr Food Sci J. 2020;3(1):126.

21. Bae YS, Shin EC, Bae YS, et al. Stress and immunity. Front Immunol. 2019;10:245-6.

22. Baden MY, Kino S, Liu X, et al. Changes in plant-based diet quality and health-related quality of life in women. Br J Nutr. 2020;124(9):960-70.

23. Zamani B, Daneshzad E, Siassi F, et al. Association of plant-based dietary patterns with psychological profile and obesity in Iranian women. Clin Nutr. 2020;39(6):1799-1808.

24. Daneshzad E, Keshavarz SA, Qorbani M, et al. Association between a low - carbohydrate diet and sleep status, depression, anxiety, and stress score. J Sci Food Agric. 2020;100(7):2946-52. 
www.yumedtext.com | January-2021 | ISSN: 2582-3264 | https://dx.doi.org/10.46527/2582-3264.130

25. Wang Y, Yip T. Sleep facilitates coping: moderated mediation of daily sleep, ethnic/racial discrimination, stress responses, and adolescent well-being. Child Dev. 2020;91(4):e833-52.

26. Sprung JM, Rogers A. Work-life balance as a predictor of college student anxiety and depression. J Am College Health. 2020;14:1-8.

27. Ip EJ, Lindfelt TA, Tran AL, et al. Differences in Career Satisfaction, Work-life Balance, and Stress by Gender in a National Survey of Pharmacy Faculty. J Pharm Pract. 2020;33(4):415-9.

28. Eganov A, Cherepov E, Romanova L, et al. Interpersonal communication of students and mental health data. J Phys Educ Sport. 2020;20:2405-08.

29. Schrodt P. Disagreement in perceptions of stepfamily communication and functioning: Implications for mental health. J Soc Pers Relat. 2021;38(1):1-20.

30. Patañjali. Patanjali yoga sutras. Chennai: Sri Ramakrishna Math, India; 1999.

31. Moszeik EN, von Oertzen T, Renner KH. Effectiveness of a short Yoga Nidra meditation on stress, sleep, and wellbeing in a large and diverse sample. Curr Psychol. 2020:1-5.

32. Strait JE, Strait GG, McClain MB, et al. Classroom Mindfulness Education Effects on Meditation Frequency, Stress, and Self-Regulation. Teaching Psychol. 2020;47(2):162-8.

33. Burgstahler MS, Stenson MC. Effects of guided mindfulness meditation on anxiety and stress in a pre-healthcare college student population: a pilot study. J Am College Health. 2020;68(6):666-72.

34. Novaes MM, Palhano-Fontes F, Onias H, et al. Effects of Yoga Respiratory Practice (Bhastrika pranayama) on Anxiety, Affect, and Brain Functional Connectivity and Activity: A Randomized Controlled Trial. Front Psychiatry. 2020;11:467-80.

35. Sukumaran S, Devi Asokan NS, Vijayan V. Using pranayama or yoga breathing to mitigate stress and anxiety during the Covid-19 pandemic. J Yoga Phys Ther Rehabil. 2020;5:1076.

36. Smitha KV. Effectiveness of Pranayama for reducing stress among adolescents (12-17 years) of selected high schools at Mangalore. Int J Nurs Educ Res. 2020;8(4):497-500.

37. Rankhambe HB, Pande S. Effect of "Om” chanting on anxiety in bus drivers. National J Physiol. Pharm Pharmacol. 2020;10(12):1138-41.

38. Samajdar SS, Mukherjee S. Effect of Gayatri Mantra Chanting on Attention, Memory, Anxiety and Mental State in Young Athletes: A Prospective Study. Int J Curr Res Physiol Pharmacol. 2020;4(3):5-7.

39. Surlya BK, Jain M, Priyamvada R, et al. Effect of Om Mantra Chanting During Examination Stress in Students. International Journal of Medical and Biomedical Studies. 2020 Feb 24;4(2), 210-212.

40. Niva WJ, Sekar L, Manikandan A, et al. Chanting as an effective intervention for stress reduction among nursing professionals - A Randomized controlled study. Adv Integr Med. 2020.

41. Crane MF, Kangas M, Karin E, et al. Leveraging the experience of stressors: the role of adaptive systematic selfreflection. Anxiety Stress Coping. 2020;33(3):231-47.

42. Maund PR, Irvine KN, Reeves J, et al. Wetlands for wellbeing: Piloting a nature-based health intervention for the management of anxiety and depression. Int J Environ Res Public Health. 2019;16(22):4413-30.

43. McMahan E, Estes D, Murfin JS, et al. Nature connectedness moderates the effect of nature exposure on explicit and implicit measures of emotion. J Posit School Psychol. 2018;2(2):128-48. 
www.yumedtext.com | January-2021 | ISSN: 2582-3264 | https://dx.doi.org/10.46527/2582-3264.130

44. Reynolds L, Rodiek S, Lininger M, et al. Can a virtual nature experience reduce anxiety and agitation in people with dementia? J Hous Elderly. 2018;32(2):176-93.

45. Yin J, Yuan J, Arfaei N, et al. Effects of biophilic indoor environment on stress and anxiety recovery: A betweensubjects experiment in virtual reality. Environ Int. 2020;136:105427.

46. Balasubramanian BA, Cohen DJ, Jetelina KK, et al. Outcomes of integrated behavioral health with primary care. J Am Board Fam Med. 2017;30(2):130-9.

47. Crocker RL. University of Arizona Andrew Weil Center for Integrative Medicine: Lifestyle Medicine Approaches in an Integrative Primary Care Model. Creating a Lifestyle Medicine Center: From Concept to Clinical Practice. 2020;4:335-44.

48. Kemp AH, Quintana DS. The relationship between mental and physical health: insights from the study of heart rate variability. Int J Psychophysiol. 2013;89(3):288-96.

49. Chalmers JA, Quintana DS, Abbott MJ, et al. Anxiety disorders are associated with reduced heart rate variability: a meta-analysis. Front Psychiatry. 2014;5:80.

50. Kemp AH, Brunoni AR, Santos IS, et al. Effects of depression, anxiety, comorbidity, and antidepressants on restingstate heart rate and its variability: an ELSA-Brasil cohort baseline study. Am J Psychiatry. 2014;171(12):1328-34.

51. Mather M, Thayer JF. How heart rate variability affects emotion regulation brain networks. Curr Opin Behav Sci. 2018;19:98-104.

52. Petrocchi N, Cheli S. The social brain and heart rate variability: Implications for psychotherapy. Psychol Psychother Theory Res Pract. 2019;92(2):208-23.

53. Pert C. Molecules of emotion: The science between mind-body medicine. NY: Simon \& Schuster, USA; 1999.

54. Bareeqa SB, Ahmed SI, Samar SS, et al. Prevalence of depression, anxiety and stress in china during COVID-19 pandemic: A systematic review with meta-analysis. Int J Psychiatry Med. 2020;27:0091217420978005.

55. Barzilay R, Moore TM, Greenberg DM, et al. Resilience, COVID-19-related stress, anxiety and depression during the pandemic in a large population enriched for healthcare providers. Transl Psychiatry. 2020;10(1):1-8.

56. Le H, Khan BA, Murtaza S, et al. The Increase in Suicide During the COVID-19 Pandemic. Psychiatric Ann. 2020;50(12):526-30.

57. Imbalance A. Nutrients and botanicals for treatment of stress: Adrenal fatigue, neurotransmitter imbalance, anxiety, and restless sleep. Altern Med Rev. 2009;14(2):114-40.

58. Hilfiker R, Meichtry A, Eicher M, et al. Exercise and other non-pharmaceutical interventions for cancer-related fatigue in patients during or after cancer treatment: a systematic review incorporating an indirect-comparisons meta-analysis. Br J Sports Med. 2018;52(10):651-8.

59. Misra R, McKean M. College students' academic stress and its relation to their anxiety, time management, and leisure satisfaction. Am J Health Stud. 2000;16(1):41-51.

60. Gross JJ. Emotion regulation: taking stock and moving forward. Emotion. 2013;13(3):359-65.

61. Damianakis T, Wilson K, Marziali E. Family caregiver support groups: spiritual reflections' impact on stress management. Aging Ment Health. 2018;22(1):70-6.

62. Yadav I, Kumar A. Balancing work and parenting demands through spiritual practices. Res J Soc Sci. 2018;9(5):7380. 
www.yumedtext.com | January-2021 | ISSN: 2582-3264 | https://dx.doi.org/10.46527/2582-3264.130

63. Fredrickson BL. The role of positive emotions in positive psychology: The broaden-and-build theory of positive emotions. Am Psychologist. 2001;56(3):218-26.

64. Goyal M, Singh S, Sibinga EM, et al. Meditation programs for psychological stress and well-being: A systematic review and meta-analysis. JAMA Inter Med. 2014;174(3):357-68.

65. McMahan EA, Estes D. The effect of contact with natural environments on positive and negative affect: A metaanalysis. J Posit Psychol. 2015;10(6):507-19. 